\title{
A Systematic Review on Age 11-16 Ethnic Minority Students' Attitudes Toward Science and Aspirations for Science Careers
}

\author{
Shu-Nu Chang Rundgren ${ }^{1}$ \\ Yuling Sun \\ Department of Education, Stockholm University, Stockholm, Sweden
}

Doi: 10.19044/ejes.v5no4a1

URL:http://dx.doi.org/10.19044/ejes.v5no4a1

\begin{abstract}
Ethnic minority students have long been underrepresented in the field of science due to social, cultural and economic factors. Understanding how their attitudes toward science and aspirations for science careers formed and developed during secondary educational level is critical to support them live their full potential for science. Numerous studies have been conduced on this topic, however a systematic examination of these studies is lacking. This research is a systematic literature review that aims to select and investigate empirical studies in the ERIC database in the timeframe from 2005 to 2017 to understand age 11-16 ethnic minority students' attitudes toward science and their aspiration for science careers. A total of 10 literature with empirical studies were identified after screening the literature with specific criteria. The factors that influence ethnic minority students' attitudes toward science and their aspiration for science careers are presented. The limitations in the previous research are discussed to provide recommendation for future research.
\end{abstract}

Keywords: Science education, attitudes toward science, aspirations for science careers, secondary education, literature review.

\section{Introduction}

Investigating students' affective factors such as attitudes and aspirations toward science contributes to a more holistic picture of the student perspective in science education together with research that focus on cognitive assessments. Maintaining positive attitudes and interests in science is not only the learning objective in most school curricula worldwide, but also is critical to foster students as citizens to respect and appreciate science as part of the

1 Corresponding author 
culture of society (Sjøberg \& Schreiner, 2010). Even if the scientific facts, concepts or theories were forgotten, the scientific way of thinking, as well as the "ethos" or "atmosphere" of the subject remains long time after the school is over (Sjøberg \& Schreiner, 2010, p. 4). Moreover, attitudes and aspirations serve as indicators for future educational choices for students. The deeper understanding of what constitutes students' attitudes and aspirations in science, the better can educators and policymakers predict what students' education choices; and further develop educational interventions at an early stage to promote students' interests in pursuing science careers.

Students' attitudes toward science have long been concerned by researchers and policymakers for it not only links to how students understand and appreciate scientific explanatory hypotheses in the material and natural world, but more importantly indicates how they aspire to become the next generation of scientists (Tytler \& Osborne, 2012). It has been demonstrated that the majority of young people hold positive attitudes toward science at age 10 (Murphy \& Beggs, 2005), however, the decline of students' positive attitudes as they turning older has been widely acknowledged, especially in developed countries (Potvin \& Hasni, 2014). At the same time, studies have shown the significance of adolescence in determining students' attitudes and aspirations for careers for future development (Tai, Liu, Maltese, \& Fan, 2006; DeWitt et al., 2011). By age 13 or 14, most students' attitudes toward science are well established and are progressively harder to change after that age period (DeWitt et al., 2011). These findings drew attention from researchers and educators to value the secondary education level period as critical for attaining students' attitudes and aspirations toward science continuously.

In addition, it was found that women and students from ethnic minority groups were facing more obstacles and much less likely than White males to enter occupations in science-related fields (Campbell, Denes, \& Morrison, 2000). Although students from ethnic minority groups had overall positive attitudes toward science, the majority of them showed the lack of aspirations for continuing studying science and pursuing science careers (Tai et al., 2006). At the same time, external factors such as limited support from families, relatively low socio-economic status and low educational attainment kept them "opting out" the educational pipeline of science even if they aspired for a science career (DeWitt et al., 2011).

Thus, it is important to examine ethnic minority students' attitudes toward science and their aspiration for science careers in secondary educational level, especially with an emphasis on the gender perspective. The significance of encouraging women and students from ethnic minority groups in science education not only lies in re-evaluating human resources, but also in increasing the potential to reduce gender and racial gaps in income and occupational prestige for social inclusion (Perry, Link, Boelter, \& Leukefeld, 
2012). With the aim of contributing to the continuous development of science, science education and social inclusion for ethnic minority students in both genders, this article presents the outcomes of a systematic literature review of empirical studies concerning ethnic minority students' attitudes toward science and aspirations for science careers. Critical reflections are made based on previous studies' theoretical framework, methods used, empirical findings and how future research can be focused to fill in the identified limitations and gaps.

\section{Research Method}

A systematic review examining studies that focus on ethnic minority students' attitudes toward science and aspirations for science careers was conducted in this research. The method applied for the literature review was following Arksey and O'Malley's framework (2005), which includes identifying research questions, identifying relevant studies and, selecting relevant studies, charting the data, and reporting results.

The aim of the review is to explore ethnic minority students' attitudes toward science and their aspiration for science careers, with a focus on secondary education level where students' age range from 11 to 16 . To provide knowledge on the state of art and further give recommendation on research to increase the percentages of science majors, the research questions are specified into three including:

1. What factors do influence their attitudes?

2. What factors do influence students' aspirations?

3. What are the limitations in the previous research?

The review applied the online database ERIC with three keywords including "attitudes toward science", "ethnic minority students" and "career choice" to identify a specific range of studies. Afterwards, the inclusion criteria as illustrated in Table 1 were developed to narrow down the studies used in this review. The selection of literature of this review work was based on the time period of the last 12 years (2005-2017), since the Relevance of Science Education (ROSE) project was initiated in 2005. ROSE provided a valid and reliable instrument to assess students' attitudes toward science and aspirations for science career, and served as an influential foundation for comparing students' attitudes toward science on an international scale (Sjøbeg \& Schreiner, 2005). 
Table 1. The inclusion and exclusion criteria for the literature selection

\begin{tabular}{|l|l|}
\hline \multicolumn{1}{|c|}{ Criteria } & \multicolumn{1}{|c|}{ Inclusion } \\
\hline 1. Time Period & The last 12 years (2005-2017) \\
\hline 2. Study Focus & $\begin{array}{l}\text { Secondary education period (including formal, informal and non- } \\
\text { formal educational contexts) }\end{array}$ \\
\hline $\begin{array}{l}\text { 3. Literature } \\
\text { Focus }\end{array}$ & $\begin{array}{l}\text { Studies looking into ethnic minority students' attitudes toward science } \\
\text { and aspirations for science career }\end{array}$ \\
\hline 4. Sample & $\begin{array}{l}\text { Ethnic minority students in secondary education level from age 11 to } \\
16\end{array}$ \\
\hline
\end{tabular}

Following, the literature selection process was conducted (Figure 1). Based on the three keywords, a total of 1472 literature were initially identified in ERIC database retrieved on 16th of November in 2017. After excluding the literature studies that were conducted out of the timeframe (criteria 1) and were not in the secondary educational level (criteria 2), 76 studies remained. Then the second round of selection was done after applying the excluded criteria 3 and 4, only 21 studies fitted into the aim of this review. After reading abstracts of articles. After excluding reports (non-empirical studies), only ten literature that fitted into the aim of this review were finally selected.

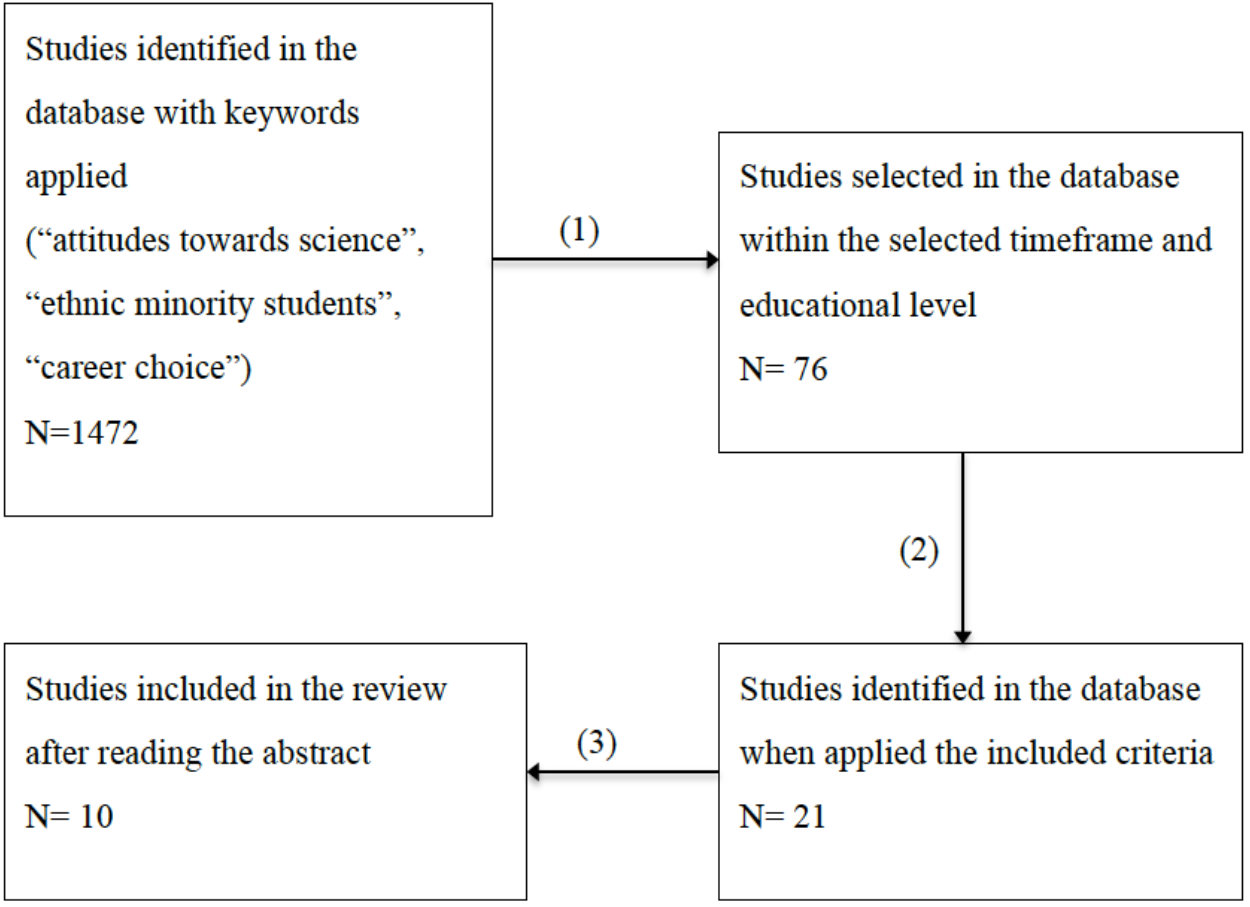

Figure 1. Literature selection process 


\section{The findings}

This section synthesizes the research findings to draw a portrait of what ethnic minority students' attitudes toward science and aspirations for science career were, and the related factors related to them. The limitations identified in the literature are also presented in order to give recommendation for future research.

\section{Ethnic minority students' attitudes toward science}

In general, White and Asian students had generally more positive attitudes and higher aspirations than other students of colour (Perry et al., 2012; Wong, 2012). Perry et al. (2012) also pointed out that pervasive differences were seen in African American students. They reported lower confidence in completing science courses and higher anxiety toward science compared to their White peers. At the same time, Latino students were reported to have lower educational aspirations and report receiving lower parental aspirations relative to White students (Perry et al., 2012).

When concerning gender, Anastasiadou, Angeletos and Vandikas (2010) identified the consistent finding that first-generation immigrant girls possessed more positive attitudes toward physics than boys. However, no significant gender difference was found by Navarro, Förster, González and González-Pose (2016) in Spanish language environment using TORSA. Perry et al. (2012) reported that girls outperformed boys with higher self-esteem and higher aspirations in an informal educational setting. When looking at students' attitudes over time, Ing and Nylund-Gibson (2017) found that fewer female students (29\%) than male students (41\%) have a very positive attitudes toward science at an early time (in the seventh grade), however, this attitudes toward science were not stable and male students' attitudes dropped over the time. In the 12th grade the percentage of students holding very positive attitudes were approximately similar among males (34\%) and females (32\%). It was also shown that males and females were equally likely to change their attitudinal profiles over time (Ing \& Nylund-Gibson, 2017).

However, the picture is more complicated when looking at ethnicity and gender together. Perry et al. (2012) pointed out that the adverse effect of being Latino or African American operate almost exclusively for boys regarding educational and science attitudes. The predicted value of self-esteem for African American girls is similar to that of White girls and White boys while African American boys is significantly lower (Perry et al., 2012). The same trend goes to Latino girls. However, study conducted by Riegle-Crumb, Moore and Ramos-Wada (2011) showed a different picture. This study indicated that ethnic minority boys tended to have rather similar attitudes toward science and math compared to White boys. However, the achievement of Black and Hispanic male students fell behind of White male students by a 
large margin. According to Riegle-Crumb et al. (2011), females from all background tended to have less enjoyment and self-concept in science than White male students. Ing and Nylund-Gibson (2017) found that females from ethnic minority groups/underrepresented who showed the qualified positive profile in early age were more likely to transit to less positive profiles compared to females that were not underrepresented.

\section{What factors did influence their attitudes?}

Anastasiadou et al. (2010) stated that the location of the school appears to be a cause for some specific negative attitudes of first-generation immigrant students toward physical science. Anastasiadou et al. (2010) also pointed out that students' attitudes toward physics were affected by parents' education levels and occupations, these two factors influenced the social economic status (SES) of the family. Perry et al. (2012) reported that household income had a negative impact on school self-esteem for girls but positive effects for boys. In relation to science, household income had almost no influence on girls' feelings of anxiety toward science but has a strong and negative effect on boys (Perry et al., 2012). Perry et al. (2012) especially pointed out the multiplicative effects of gender and disadvantaged ethnic or SES groups. The combination of being both male and either from the social-economic disadvantaged background or ethnic minority groups were more likely to influence students' attitudes and decisions about science education and careers (Perry et al., 2012).

Wong (2012) conducted an in-depth case study of two 13-year-old British Asian girls regarding their attitudes and self-identification with science. The study showed that both two girls' self-identification with science was highly influenced by social and cultural capitals. Although one girl's interests in science were decreasing since she entered secondary school, she chose to challenge the most difficult triple science class based on her desire to identify with her construction of the subject as being "smart and clever" (p. 59). She also had various recourses available from her parents, older brother and uncle to assist her to continue studying science. On the other hand, the other girl showed little interest in triple science because she desired to enter the show business and becoming famous and she kept up her grades in science mainly because her mom was strictly supervising her schoolwork. Wong (2012) argued that the differences between these two girls in social and cultural capital in science result in different forms of identity performativity (being "clever" and being "famous") and educationally oriented habitus of ("long-term" of challenging harder science courses and "short-term" of getting good grades) (p. 61).

\section{Aspirations for science careers}

Who aspires science careers? Results of the quantitative study by 
DeWitt and Archer (2015) showed that, at year 6, 7.8\% of all students held strong aspirations in pursuing science careers, and among them $60.7 \%$ were White, $18.2 \%$ were South Asian, 9.4\% were Black and 9.5\% were other ethnicities. When it came to year $9,8.5 \%$ of the whole student held strong aspirations, percentages among different ethnic groups slightly changed but the significant gap still remained with 57.1\% White, 21.9\% South Asian, 8.4\% Black and $11.7 \%$ other.

However, concerning the likelihood of students to fell in the group that holds strong aspirations in science, the results seemed to be at contradictory with the prediction by Logistic multilevel models (MLM) (DeWitt \& Archer, 2015). The models showed the factors that most strongly predicted whether or not a child is likely to strongly aspire for the science career, and these factors include gender, ethnicity (Black, Other and Asian), cultural capital (high and very high), science set or family background. Specifically speaking, compared to White male students from the medium cultural capital, girls were less likely than boys to have strong aspirations; Asian students, as well as Black and other ethnicities were more likely than White students to fell into this group. Students with high or very high cultural capital were more likely to hold strong aspirations than students from medium or low levels. And finally, students who were in the top set for science and have family connections to science field are twice as likely to fall into the group (DeWitt \& Archer, 2015).

The prediction was confirmed by another quantitative study by Rodrigues, Jindal-Snape and Snape (2011) examining Scottish students' aspirations. Results showed that only $40 \%$ of Scottish male and $32 \%$ of Scottish female were considering a career in science, in comparison with Pakistani-related pupils, $85 \%$ of Pakistani-related male students were considering a career in science while only $22 \%$ of females were considering a career in science. Riegle-Crumb et al. (2011) applied logistic regression analysis to predict student's aspirations for science careers for White, Black, and Hispanic students. Results showed that with the exception of Black male students, youth from other ethnic and gender subgroups were significantly less likely than White males to desire a science career.

\section{What factors did influence students' aspirations?}

Perceived parental and peer attitudes. DeWitt and Archer (2015) pointed out that, in both Year 6 and Year 9, students' aspirations in science were mostly influenced by perceived parental attitudes to science and their own attitudes and experiences of school science. Ethnicity and gender differences were seen according to Rodrigues et al. (2011) when examining students' perceived parental and peer attitudes. Compared to very few Scottish British male and female students perceived their parents thought science careers were better, students from ethnic minority backgrounds perceived 
more importance from their parents' attitudes. It was found that $89 \%$ of Other Asian (Indian, Chinese, other Asian) males, 64\% Others (European, AfroCaribbean) females, $62 \%$ of Pakistani-related males and females thought their parents value the importance of science (Rodrigues et al., 2011). And among certain groups (Pakistani-related males and Other Asian males), students thought that their parents thought science careers were best even though their parents were not interested in science and did not consider science to be important (Rodrigues et al., 2011). Rodrigues et al. (2011) pointed out that there was a moderate positive correlation between the percentage of students who thought that their friends thought science careers were the best and the percentage of students who aspired for science career. Perceived parental attitudes had a stronger impact on how ethnic minority students aspired for science careers.

Self-identification with science. Two qualitative studies in this review also revealed how a typical scientist figure picture made science career unattractive for ethnic minority students, particularly for girls (Wong, 2015). In the interviews conducted with 46 ethnic minority students, majority of them (42 students) expressed that "anyone can be a scientists", if they were clever or work hard. However, more than half of the students also associated scientists with certain social identities, where scientists were more stereotyped in terms of gender (e.g. "for men", "manly-ish") and ethnicity (e.g. "for white people"). It was shown that 16 out of 26 boys and 13 out of 20 girls reinforced the traditional gender stereotype statement that "scientists are mostly men" (Wong, 2015). An Indian boy implied that the dangerous nature of science when sometimes people got hurt, so science was not suitable for women. A similar statement was made by a Chinese boy that science was "not good for women, it doesn't suit their kind". Such statements were also heard from girls, an Indian girl thought that science was a "man's field", because women needed to do housework and another Indian girl said she would feel "strange", if she saw scientists were not men (Wong, 2015).

Wong (2015) pointed out that identifications with science could be particularly difficult for females from ethnic minority groups because the dominant discourse of scientists was not only gendered but also racialized. The images of scientists were specifically represented and reinforced as White men (Wong, 2015). A Bangladeshi boy stated that most well-known scientists were "European, Western, White". It is also important to note that some students had recognized the potential barrier of racism in pursuing a science career. For example, an Indian girl speculated that Black people might get disencouraged from most White scientists. Another Indian girl confirmed this point of view stating that an Asian girl might change her mind about becoming a scientist when she had "never seen an Asian scientist" (Wong, 2015). 
Science capital. Archer, DeWitt and Willis (2014) defined science capital as a conceptual device that combines various types of economic, social and cultural capital that specifically relate to science. Wong (2015) pointed out that these resources related to science learning could strengthen or weaken students' aspirations toward, and identifications with, science and science careers. Having family members using science in their work and science set were particularly important for students in ethnic minority groups to aspire a science career. Results from DeWitt and Archer (2015) showed that students who had a family member working in a science-related job were 2.16 time more likely to fall into the group that strongly aspired for a science career than those who did not.

Another aspect related to science capital is the economic, social and cultural status and rewards that science brings as a career. Based on the distinction that Wong (2015) made between careers in science and careers from science, Wong (2015) also pointed out that careers from science (e.g., medical doctor, engineer, IT/games developer) seemed to be more attractive among ethnic minority students. These professions were more identifiable to ethnic minority students for these professions were generally considered to be good financially rewarding, more intelligible for "people like us" and had good reputation endorsed by family/community members. At the same time, the Indian British girl pointed out in the case study by Wong (2012) that her parents and members of her extended family viewed careers in the field of medicine and law as desirable professions because of financial secure and social status that those professions brought.

Experience of school science. Analyses by DeWitt and Archer (2015) revealed that attitudes and experiences to school science and parental attitudes to science were the most closely influential factors for students' aspiration in science. At the same time, structural factors including gender, ethnicity and cultural capital strongly influenced students' attitudes, experience and participation of science in school and out of school. DeWitt and Archer (2015) found that despite students' positive attitudes toward school science, the gap remained between their attitudes and aspirations in science. It was found that students' enjoyment of science lessons seemed to decrease over time for both Year 6 and Year 9 students.

\section{Limitation of selected studies}

Studies included in this review revealed several limitations when examined individually and as a whole. This section regards all studies in this review altogether and examines the limitations from a macro perspective. Gaps found from previous researches are presented to serve as guidelines, to give recommendation for future researches. 


\section{Validity and reliability of the instrument}

Research instrument under this topic serves as measurement tools for grasping ethnic minority students' attitudes toward science and aspirations for science careers. The key constructs for developing and also assessing research instruments are their reliability and validity (Tytler \& Osborne, 2012). As Messick (1989) emphasized, constructing validity of an instrument depends on the extent that the items being measured are supported by a good theoretical foundation, so it is clear that what the instrument is attempting to measure and why it would be considered important to be measured (Tytler \& Osborne, 2012). On the other hand, constructs such as "attitudes toward science" and "aspiration for science career" are underlying unitary constructs synthesized from multiple components. In this case, internally consistent and unidimensional are considered important to make sure the psychometric principle of applying the instrument (Tytler \& Osborne, 2012).

Two studies included in this review examined and confirmed validity and reliability of selected research instruments (Anastasiadou et al., 2010; Navarro et al., 2016). Meanwhile, there were other two studies applied instruments of previous researches that validity and reliability had been proven before (Hayden, Ouyang, Scinski, Olszewski, \& Bielefeldt, 2011; Rodrigues et al., 2011). However, specific examination or statement regarding validity and reliability of applied instruments were not found in the rest four studies. Among them, three studies did not provide a solid theoretical framework to guide and support the formation of research instruments.

\section{Lack of qualitative studies}

In this review, among the 10 identified empirical studies, there were only three studies using qualitative method (Wong, 2012, 2015; Ing \& Nylund-Gibson, 2017), while quantitative method was mainly used in the rest (Anastasiadou et al., 2010; Navarro et al., 2016; Perry et al., 2012; Rodrigues et al., 2011; Hayden et al., 2011; DeWitt \& Archer, 2015; Riegle-Crumb et al., 2011). A quantitative orientation provides portraits of what students' attitudes toward science and their aspirations for science careers were, and quantified the relations between different influential variables. However, qualitative studies were found lacking in terms of why and how the related factors were supporting or hindering students from ethnic minority background to continue studying science and choosing science as careers. At the same time, why impact varies on students from different ethnic minority groups and also more negative on boys while girls seem to be resilient was not clearly examined (Perry et al., 2012). As Wong (2015) suggests in his study, the significance of future researches lies beyond just examining the numbers or patterns of students (across ethnicity) that interested in science and aspired for science career as a marker for science equity, but more importantly recognize and 
appreciate the reasons behind why and how different students participate in, or identify with, science and science careers.

\section{Conclusion}

This review includes 10 empirical studies identified in the ERIC database in order to explore age 11-16 ethnic minority students' attitudes toward science and aspirations for science careers. Despite ethnic minority students hold overall positive attitudes toward science and especially boys most expressed the aspiration for science careers, their further development is still restrained by lacking parental support, low science capital they possess, negative experiences with school science, and unable to identify themselves as scientists. These factors are all deeply patterned by gender, ethnicity and socio-economic status (Riegle-Crumb et al., 2011; Rodrigues et al., 2011; Wong, 2012, 2015).

Limitations found in the previous studies provide researchers suggestions for future studies. Research with qualitative methods are needed to deeply look into the reasons for the possible differences revealed in difference genders and among ethnic minority groups. At the same time, the quantitative studies presented in this article can be further examined the validity and reliability of their research instruments. Last but not the least, further research can focus on the gap between aspirations and actual behaviour of choosing science as careers, and providing suggestions for interventions for promote more ethnic minority students in pursuing science careers is needed.

\section{References:}

1. Arksey, H., \& O'Malley, L. (2005). Scoping studies: Towards a methodological framework. International Journal of Social Research Methodology, 8(1), 19-32.

2. Anastasiadou, S. D., Angeletos, T., \& Vandikas, I. (2010). A multidimensional statistical analysis of students' attitudes toward physics. International Journal of Diversity in Organisations, Communities \& Nations, 16, 341-356.

3. Archer, L., DeWitt, J., \& Willis, B. (2014). Adolescent boys' science aspirations: Masculinity, capital, and power. Journal of Research in Science Teaching, 51(1), 1-30.

4. Campbell, G., Denes, R., \& Morrison, C. (2000). Access denied: Race, ethnicity, and the scientific enterprise. Oxford, England: Oxford University Press.

5. DeWitt, J., \& Archer, L. (2015). Who aspires to a science career? A comparison of survey responses from primary and secondary school students. International Journal of Science Education, 37(13), 21702192. 
6. DeWitt, J., Archer, L., Osborne, J., Dillon, J., Willis, B., \& Wong, B. (2011). High aspirations but low progression: The science aspirationscareers paradox amongst minority ethnic students. International Journal of Science and Mathematics Education, 9(2), 243-271.

7. Hayden, K., Ouyang, Y., Scinski, L., Olszewski, B., \& Bielefeldt, T. (2011). Increasing student interest and attitudes in STEM: Professional development and activities to engage and inspire learners. Contemporary Issues in Technology and Teacher Education, 11(1), 47-69.

8. Ing, M., \& Nylund-Gibson, K. (2017). The importance of early attitudes toward mathematics and science. Teachers College Record, 119(5).

9. Messick, S. (1989). Validity. In R. L. Linn (Ed.), Educational measurement (3rd ed., pp. 13-104). New York, NY: American Council on education and Macmillan.

10. Murphy, C., \& Beggs, J. (2005). Primary science in the UK: A scoping study. Final report to the Wellcome Trust. London: Wellcome Trust.

11. Navarro, M., Förster, C., González, C., \& González-Pose, P. (2016). Attitudes toward science: measurement and psychometric properties of the Test of Science-Related Attitudes for its use in Spanish-speaking classrooms. International Journal of Science Education, 38(9), 14591482.

12. Perry, B. L., Link, T., Boelter, C., \& Leukefeld, C. (2012). Blinded to science: Gender differences in the effects of race, ethnicity, and socioeconomic status on academic and science attitudes among sixth graders. Gender and Education, 24(7), 725-743.

13. Potvin, P., \& Hasni, A. (2014). Interest, motivation and attitude towards science and technology at K-12 levels: A systematic review of 12 years of educational research. Studies in Science Education, 50(1), 85-129.

14. Riegle-Crumb, C., Moore, C., \& Ramos-Wada, A. (2011). Who wants to have a career in science or math? Exploring adolescents' future aspirations by gender and race/ethnicity. Science Education, 95(3), 458-476.

15. Rodrigues, S., Jindal-Snape, D., \& Snape, J. (2011). Factors that influence student pursuit of science careers; the role of gender, ethnicity, family and friends. Science Education International, 22(4), 266-273.

16. Sjøbeg, S., \& Schreiner, C. (2005, March). Young people and science attitudes, values and priorities: Evidence from the ROSE project. Keynote presentation at the European Union Science and Society Forum, Brussels. 
17. Sjøberg, S., \& Schreiner, C. (2010). The ROSE project: An overview and key findings. Retrieved from https://roseproject.no/network/countries/norway/eng/nor-SjobergSchreiner-overview-2010.pdf

18. Tai, R. H., Liu, C. Q., Maltese, A. V., \& Fan, X. (2006). Planning early for careers in science. Science, 312, 1143-1144.

19. Tytler, R., \& Osborne, J. (2012). Student attitudes and aspirations towards science. In B. J. Fraser, K. Tobin, \& C. J. McRobbie (Eds.), Second International Handbook of Science Education (pp. 597-625). Dordrecht: Springer Netherlands.

20. Wong, B. (2012). Identifying with Science: A case study of two 13year-old "high achieving working class" British Asian girls. International Journal of Science Education, 34(1), 43-65.

21. Wong, B. (2015). Careers "from" but not "in" science: Why are aspirations to be a scientist challenging for minority ethnic students? Journal of Research in Science Teaching, 52(7), 979-1002. 